\title{
CLOWN, ESE OTRO POETA. GABRIEL CHAMÉ BUENDÍA, UN VIAJE PEDAGÓGICO
}

\author{
CLOWN, THAT OTHER POET. GABRIEL CHAMÉ BUENDÍA, A \\ PEDAGOGICAL JOURNEY
}

\author{
Lydia Di Lello
}

Instituto de Artes del Espectáculo- FFyL_UBA

(licenciadalydialesser@gmail.com)

https://orcid.org/0000-0003-2634-1455

(2)

DOI: https://doi.org/10.32621/acotaciones.2020.44.03

ISSN 2444-3948

Resumen: La risa rasga el orden, desordena, instaura un mundo. El descubrimiento de que hacía reír fue el punto de inflexión de la búsqueda artística de Gabriel Chamé Buendía. Actor, director, investigador y pedagogo, este artista es una de las figuras más destacadas de la renovación del teatro argentino de postdictadura en los años ochenta. Teatrista de dimensiones nacionales e internacionales, como docente es formador de actores en múltiples ciudades americanas y europeas. Este ensayo pone el foco específicamente en su praxis docente. Este es un método acaso poco usual, pero particularmente productivo para acceder a su poética. Esta perspectiva surge como resultado de mi participación como investigadora-oyente en varios seminarios intensivos de clown dictados por el artista entre los años 2013 a 2016, en Buenos Aires. En ese período le hice varias entrevistas personales de modo de completar algunas de las cuestiones teóricas planteadas en su técnica docente. La presentación incluye información relevada en reportajes periodísticos y textos académicos sobre el arte del clown. 
Palabras Clave: Payaso, Poesía, Juego, Fracaso, Vacío, Cuerpo,Tristeza.

Abstract: Laughter tears order, messes up, creates a world. The insight that people found him funny and he could make them laugh, was the turning point of the artistic search of Gabriel Chamé Buendía. Actor, director, researcher and pedagogue, this creator is one of the most prominent figures in the renovation of the Argentine post-dictatorship theatre in the eighties. Artist of national and international dimensions, as a teacher, Buendía trains actors in multiple American and European cities. This essay focuses specifically on his teaching practice. This is an unusual, but particularly productive method to become acquainted with his theatrical poetics. This perspective arises as a result of my participation as a researcher-listener in several intensive clown seminars taught by the artist between 2013 and 2016, in Buenos Aires. During that period we shared several personal interviews to complete some of the theoretical questions raised in his teaching technique. The presentation includes information in journalistic reports and academic texts about the art of clown. The goal, in short, is to accompany the journey proposed by Chamé, a journey of discovery, that of the Clownesque language.

Key Words: clown, poetry, playing, failure, void, body, laughter, sadness.

Sumario: 1. Introducción. 2. Chamé Buendía, clown. 3. De la complejidad a la síntesis. 4. Ganarle a la mente. 5. Marcar un timing musical. 6. Ser seriamente cómico. 7. Ser fiel a un personaje. 8. Configurar el traje. 9. Desarrollar los conflictos. 10. Crear el vacío. 11. Buscar lo interior. 12. Resultados de un viaje pedagógico. 13. A modo de conclusión: Ser un clown. 14. Bibliografía. 15. Notas.

Copyright: (C) 2020. Este es un artículo abierto distribuido bajo los términos de una licencia de uso y distribución Creative Commons 4.0 Internacional (CC BY 4.0) 
Lydia Di Lello es investigadora teatral argentina, licenciada en Psicología. Investigadora del Instituto de Artes del Espectáculo de la facultad de Filosofía y Letras de la Universidad de Buenos Aires, donde se desempeñó como coordinadora del Área de Investigaciones de Oriente entre los años 2016-2019. Investigadora en el Área de Investigaciones en Ciencias del Arte del Centro Cultural de la Cooperación. Miembro de la Asociación Argentina de Investigación y Crítica Teatral. Miembro del jurado del Premio Teatro del Mundo. Trabajos publicados en varios volúmenes colectivos y en las revistas: Palos y Piedrad, Latin American Theater Review (Kansas); Stichomythia (Valencia); Conjunto de la Casa de las Américas (Cuba), Karpa (California), Cuaderno del Picadero de Shakespeare en la Argentina, Dramateatro Revista Digital. (Polonia) y $A B C, L a$ cultura del Psicoanálisis. 

Gabriel Chamé Buendía tiene el talento de hacer de su herida una sonrisa que se abre al mundo. Alain Gautré

\section{INTRODUCCIÓN}

El del clown es un universo de acciones físicas simples generadoras de póiesis teatral, un orden ontológico «otro», de alto vuelo poético. En otras oportunidades he abordado el análisis de la poética del teatro de clown a través del estudio del texto espectacular y actoral del clown Gabriel Chamé Buendía. Este ensayo, en cambio, pone la mirada en su praxis en tanto docente.

La palabra de Buendía, elemento fundamental de este trabajo, salvo explicitaciones en contrario, proviene del registro de sus seminarios entre 2013 y 2016. Mi intención es transmitir esa palabra fresca, espontánea, pero preceptiva; comunicar los tropiezos de la enseñanza y, ¿por qué no?, el placer de haber sido testigo de ese proceso.

\section{Chamé Buendía, clown}

La risa desordena e instaura un mundo trastocado. Conecta profundamente con lo que Henri Bergson llamaría cierta distracción fundamental de la persona: «como si el alma se hubiese dejado fascinar, hipnotizar, por la materialidad de una acción simple.» (Bergson, 1986, pág. 22).

De pronto, la risa. La risa que reverbera estruendosa. El descubrimiento de que hacía reír fue el punto de inflexión de la búsqueda artística de Gabriel Chamé Buendía. Actor, director, investigador y pedagogo, este artista es una de las figuras más destacadas de la renovación del teatro argentino de postdictadura en los años ochenta. Entre 1978 y 1984, se formó como actor y asistente de dirección en la Compañía Argentina de Mimo dirigida por Ángel Elizondo, discípulo de Étienne Decroux, y en los cursos de clown de Cristina Moreira, figura fundamental en la formación de comediantes a partir de técnicas de clown con la metodología de la escuela francesa de Jacques Lecoq.

Miembro fundador y actor del «Clú del Claun» (1985/90), ese grupo mítico que en la década del ochenta apostó a una estética del desparpajo, 


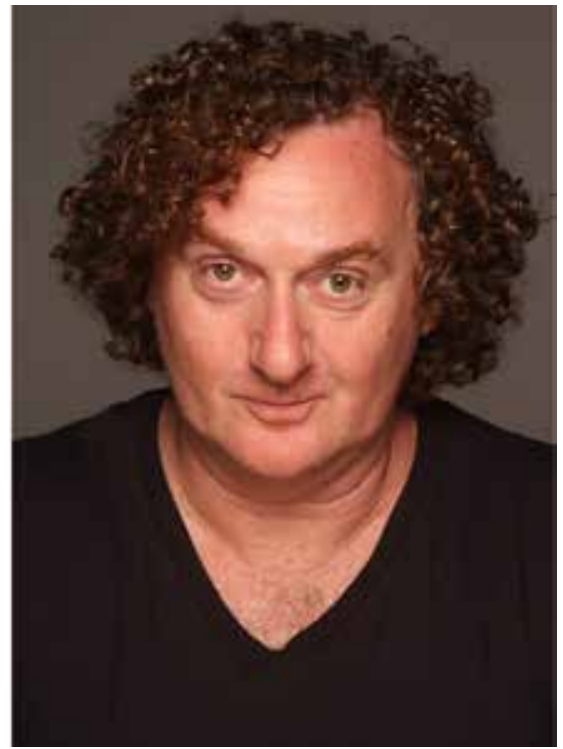

Gabriel Chamé Buendía.

Fotógrafo Gianni Mestichelli.

Chamé inauguró la presencia de los payasos argentinos dentro del «Cirque du Soleil». Teatrista de dimensiones nacionales ${ }^{2}$ e internacionales, como docente ${ }^{3}$ es formador de artistas en múltiples ciudades americanas $y$ europeas.

Clown deriva del término «clod», apunta la investigadora Beatriz Seibel, que significa «tonto, campesino». El payaso, una forma dramática que aparece en los primeros rituales de todas las culturas, se diversifica en el mundo contemporáneo en los clowns que actúan en el circo, en la calle, en el teatro, en clowns «sociales» (Payasos sin Fronteras, Clowns No Perecederos, Payamédicos, entre otros), todos con su especificidad de lenguaje.

El clown contemporáneo, quintaesencia de la estética de la multiplicidad, sostiene el doctor Jorge Dubatti, ${ }^{4}$ es el heredero histórico de los mimos grecolatinos, de los histriones medievales, de los intérpretes de la «Commedia dell'arte», de los bufones, así como de los cómicos nacionales. 


\section{De LA COMPLEJIDAD A LA SÍNTESIS}

El desempeño actoral del clown requiere una formación en diversas disciplinas. Debe ser actor, mimo, músico, acróbata, hacer malabares, incluso danza. En última instancia, este artista devendrá con el tiempo director, autor y productor de sí mismo. De modo que la tontería absoluta está resguardada por grandes conocimientos que no aparecen en un primer plano sino detrás, pero que tienen un peso enorme. La aparente pobreza del payaso, diría Buendía, está sustentada por el manejo de una multiplicidad de artes. Esa polifonía converge en una síntesis, la poesía del clown. «El gran lenguaje del payaso — dice Chamé- es la simplicidad». 5

Los seminarios impartidos por el artista son una experiencia iniciática en esa dirección. Los actores comienzan una travesía a través de juegos, ejercicios de escena que confluyen en una exhaustiva devolución por parte de Chamé. Lo central es la improvisación, la práctica más eficaz para empezar a comprender el mecanismo propio de cada actor, conocer las formas personales. Este trabajo constituye una vía del autoconocimiento del yo interno, de la propia intimidad, en un profundo y personal contacto con la posibilidad del fracaso y el ridículo en la búsqueda del propio clown. Esta búsqueda es una investigación del lugar irrisorio de uno mismo, un descubrimiento de la parte clownesca que habita a cada uno.

El clown se construye desde el «yo borrado» - diría Cristina Moreira-, un yo que ha quedado marginado, el ingenuo, que en el juego artístico del clown se despabila desandando el camino hacia la infancia perdida (Moreira, 2008, pág. 43).

\section{Ganarle a la mente}

Es necesario recuperar la capacidad de jugar. El juego es un concepto teatral fundamental cuando del lenguaje del payaso se trata. El juego se aparta de la vida, es «algo que no es verdad — asegura Chamé a sus alumnos-, una transposición poética»:

Mientras juego, gano o pierdo; cuando alguien me está ganando lo odio, sin embargo, no tengo un problema personal con él porque es un juego. «Lo importante - afirma el maestro- es sostener el juego todo el 
tiempo. En el momento en que ustedes hablan de sufrir es porque hay un lugar donde dejaron de jugar, están tomando lo que está pasando como una realidad». Cuando las exigencias personales se imponen sobre el placer del juego, inmediatamente algo se pierde y comienza - afirma Chamé- el tránsito sufridor del alumno.

La simplicidad de los juegos es que, una vez conocidas las reglas, simplemente hay que jugar. No hay preguntas internas, no debe tamizarse la acción con el filtro de la mente, simplemente se hace. Eso es profundamente clownesco, profundamente payaso. De modo que un objetivo fundamental en la formación del alumno tiene que ver con lograr «no soltar el juego». Esto, que vale para los juegos que se practican a modo de aprendizaje, vale también para la escena:

En la escena - explica el docente-, cada vez que se ponen a pensar, pierden. Hay que no pensar y reaccionar, darte cuenta más rápido con tu cuerpo que con tu mente. Cuando quieres traducirlo a la mente en ese momento se para el juego. La mente frena, está diciendo no, no se quiere jugar, no se quiere arriesgar. Pero si se le da prioridad al cuerpo, el cuerpo gana. Inmediatamente la mente pierde control porque el placer del juego predomina.

En la escena se trata de encontrar el impulso, el mismo impulso del placer del juego. Hay momentos clave -explica el docente- en los que el actor en escena debe arriesgarse, jugarse para salvar un espectáculo. Ese momento de riesgo, en el aquí y ahora de la escena, es muy emocional pero no debe quedarse en la emoción, sino transformarse en algo físico inmediatamente. El término «emoción», según Lecoq en la perspectiva de Chamé, significa etimológicamente «poner en movimiento». Dice Chamé:

Entras en la acción, no te quedas en el sentimiento. El peso psicológico en este lenguaje teatral frena, no ayuda. Se busca que una sensación emocional potente nos lleve a una acción determinada. Es visceral, es tanto lo que sientes que tienes que hacer algo. Lo sientes, lo haces. Si lo frenas estás desafinado, si lo aceleras estás desafinado. Eso es la desafinación. 
Esta noción de lo afinado o lo desafinado se asocia con el concepto de «timing», de estar en el presente, otro tema nodal en la técnica del clown. «Estar en el presente» no es más que estar en un tiempo tan preciso y efímero como un chasquido. Chamé lo explica con sencillez: «No reflexionar permite no frenar, si frenas pierdes el tiempo, si pierdes el tiempo se siente que estás fuera de tiempo y si estás fuera de tiempo no estás en el presente, estás pensando en lo que va a venir o pensando en lo que pasó. No eres verdadero».

Hacer no es necesariamente moverse, es «estar presente». Esta calidad del presente se juega particularmente en el «gag».

\section{Marcar un timing musical}

La manera de contar del payaso es con acciones físicas, juegos, locuras. «Soy muy matemático con el humor, dice Chamé. Para que un gag funcione hay que hacer una observación microscópica: ritmos, tiempos, emociones y precisión física. Quizá lo que no estás haciendo es esa pequeña respiración en el medio y es eso lo que causa gracia». Todo está marcado rítmicamente y un gag es un timing musical.

En el trabajo del clown el gag no es pensado. Es la presencia del payaso frente al público lo que vale. Lo que le provoca al público y cómo se comunica con él. Es importante que la acción fluya y, cuando el gag aparece, registrarlo para integrarlo a los recursos escénicos. Se requiere precisión para saber cuan estirado está, cuándo concluye el gag y cuan bien rematado está.

El clown Walter Velázquez pone el acento en la diferencia entre «hacerse el gracioso» o estar en «estado de gracia». «Siempre el humor nace de lo que le pasa a uno. El clown está padeciendo todo el tiempo lo que le pasa, está transitando su momento. Es importante, entonces, que el alumno aprenda a no hacerse el gracioso, tiene que transitar la situación.» (Grandoni, 2006, pág. 226).

\section{Ser seriamente cómico}

Lo trágico siempre está sosteniendo la carcajada. El cuerpo disponible del clown se expone ante un público que se ríe de sus debilidades 
porque las reconoce como propias. Se expone, no se exhibe, diferencia Guillermo Angelelli (Grandoni, 2006, pág. 168); lo suyo no es mostrarse como quien está en una vidriera. Lo suyo es exponerse, estar abierto.

«El buen payaso es un multiplicador de problemas. Lo que es terrible para ti, dice Gabriel, es muy cómico para los otros». Él procura que el alumno concientice el aspecto trágico cómico para que tenga más peso lo que hace. «Enseño el humor desde un lugar de gravedad — sostiene el artista-. Me gusta que en el dolor haya un respiro. No como evasión, sino como una manera más inteligente de ver la dificultad.» (Chamé en Yaccar, 2010, pág. 12).

Nos dice Chamé:

Una cosa es la seriedad de la comicidad, hay que ser muy serio para poder entender lo grave de lo que se está tratando, para que eso tenga un peso cómico. Busco que el actor tome conciencia. Que, cuando alguien tiene esta particularidad técnica, no la pierda después con la automatización de las cosas que ya funcionan. Todo es una cuestión práctica de trabajo, que la persona no se evada de lo que está haciendo, que se meta cada vez más a fondo. No pasa por la cabeza, pasa por un estado anímico y físico, un estado lúdico. El estado de placer, el estado de miedo, no se pueden explicar intelectualmente. Se viven física y emocionalmente. La gente ríe del hecho trágico, el payaso lo sabe y busca que se liberen estas cosas. La especificidad de su lenguaje -continúa Chamé- es la risa, la poesía, la tristeza. ${ }^{6}$

El clown es un antihéroe. En contraste con la perfección del acróbata, el clown quiere hacer algo y fracasa. El fracaso no es el final de algo, es el comienzo de toda una serie de acciones. El trabajo clownesco - diría Lecoq - consiste en poner en relación la proeza y el fracaso: «Pedidle a un clown que haga un salto mortal y no lo conseguirá, dadle una patada en el trasero y dará un salto mortal como si tal cosa.» (Lecoq, 2004, pág. 214).

El clown juega con lo místico. Cree sin dudar en lo que está haciendo. Si un payaso dice «voy a levitar», el payaso finalmente va a levitar —asegura Chamé. Si el actor empieza a decir «no puedo», se acabó el payaso. No tiene que abandonar el juego nunca y, por sobre todo, debe creer que es posible. Es la inocencia del payaso: «te pones esa meta y no sabes qué vas a hacer $y$ de repente, por ponerte esa meta te pones a hacer cualquier 
cosa. Y la gente se muere de risa por el hecho también trágico de que tú estás queriendo levitar. Y, de repente, levitas.» ${ }^{7}$

\section{SER FIEL a Un PERSONAJE}

«El arte del payaso es un arte que tiene que ver con lo popular y que tiene que ver con la fidelidad a un solo personaje», dice Chamé. ${ }^{8} \mathrm{~A}$ diferencia del actor que interpreta diferentes personajes, el clown renuncia a esta multiplicidad. Hace un personaje para toda la vida, aunque, desde luego, este se va enriqueciendo con la madurez del payaso.

Hay una relación inextricable entre actor y personaje, pero están separados. «Mr. Piola, mi personaje, dice Gabriel, es una entidad en sí.» (Chamé en Yaccar, 2010, pág. 12).

Ahora bien, el clown es un personaje que a su vez puede interpretar a otro personaje. Chaplin es Charlot, que puede travestirse e interpretar a Carmen. Hay una suerte de juego de identidades. Una puesta de distancia que involucra cierto extrañamiento. Algo muy fuerte y distintivo es que el actor que es un clown interpreta a un personaje, pero el clown está siempre entremedio.

Es una filosofía, explicita Chamé. Mi personaje es alguien que va a estar ahí. Está bueno que ayude con la libertad imaginativa y expresiva, que apunte a una búsqueda más corporal, a reencontrar su infantilidad, su tontería. Porque el actor quiere entender la lógica del personaje: por qué hace eso y cómo. El clown se preocupa sólo por el cómo» (Chamé en Yaccar, 2010, pág. 12).

Peter Brook afirma, a propósito del arte del actor:

El medio expresivo del actor es el traicionero, mudable y misterioso material de sí mismo. Se le pide que se comprometa por completo y al mismo tiempo que se distancie: desapego sin desapego. Ha de ser sincero e insincero: debe practicar cómo ser insincero con sinceridad y cómo mentir con verdad. (Brook, 2002a, pág. 174).

Si esto es así en el actor en general, más aún lo es cuando se trata del arte del clown, donde cada uno tiene que potenciar algo de sí mismo 
para poder conseguir un hecho cómico y un hecho expresivo. Ser «materia disponible», diría Lecoq, en un juego de fuerte conexión y, a la vez, de cierto distanciamiento afectivo con el público.

Todos tenemos, diría Lecoq, un «fondo poético común»; esto es, una dimensión abstracta, hecha de espacios, de luces, de colores, de materias, de sonidos que se encuentran en cada uno de nosotros a partir de nuestras diversas experiencias. «Todo eso queda en nuestro cuerpo y constituye el fondo común a partir del cual van a surgir los impulsos, los deseos de creación.» (Lecoq, 2004, pág. 75). Cada persona, entonces, es como un territorio, un fondo inconmensurable en el que bucear $y$ en el que lo biográfico - el lenguaje, la gestualidad, la lógica propiasse vuelve material de trabajo» (Grandoni, 2006, pág. 32). En el surgimiento del clown se trabaja sobre ese fondo personal. Y a partir de esa base profunda es preciso volar, no quedarse en lo personal. Lo que le pasa a cada uno es interesante en sí como código para después transformarlo en escena. Poner la esencia personal de cada uno a favor, lograr fluidez en escena.

El clown está permanentemente en crisis, pero - sostiene el docente- lo importante no es la profundidad de la crisis, lo que importa es él: «Lo fundamental es quién es este tipo, quién es esta esencia, quién es este estúpido.» El clown tiene que ver con lo ridículo de cada uno, con el propio imaginario subjetivo e intransferible.

\section{Configurar el traje}

En el proceso de construcción poética aparece el traje del clown. El docente ayuda a los actores en la configuración de la imagen. Los alumnos traen prendas que se van probando bajo la mirada del maestro. Del perfil que haya ido apareciendo a lo largo de la experiencia de aprendizaje, los juegos, los ejercicios escénicos, se va armando la apariencia, lo que conviene exaltar o disimular en cada clown.

Chamé postula la simplicidad, lo importante es no caer en estereotipos. Puede ser muy simple, ciertos elementos que activen a cada uno, prendas, acaso detalles, que impulsen el juego, que disparen la imaginación. Lo que se busca es que el traje no sea demasiado cerrado, es decir, tan jugado a un personaje que no permita la apertura. Los vestidos del 
clown deben albergar cierta ambigüedad, desestructurar lo demasiado armado para permitir grados de libertad.

El profesor no descuida tampoco los elementos, como maletas u otros objetos útiles para la escena, cuyas características también variarán de acuerdo con la singularidad de cada clown.

Durante el seminario, el análisis de los trajes se hizo en grupos. Todos los participantes con la nariz roja puesta. La nariz puede estar o no, a criterio de cada clown. «Lo importante — afirma Gabriel— es el estado clownesco interno, la capacidad de encontrar algo y desarrollarlo, estar en un estado emocional creativo».

Pero la nariz es para Chamé material pedagógico. En primera instancia, el docente instruye en el cuidado de esa pequeñísima máscara; no es un elemento más. En los ejercicios escénicos los alumnos pasan a escena, de espaldas se colocan la nariz y giran. Ya son clowns que reaccionan al redoble de un pandero. Cuando el ejercicio termina, nuevo redoble, un «muchas gracias» e inmediatamente llega la orden de sacarse la nariz para escuchar la devolución. En el cruce de esta frontera entre la ausencia o presencia, entre dentro o fuera de escena la nariz es, entonces, una materia particularmente significativa.

El momento de la configuración del traje se expande hacia las consideraciones sobre la elección del nombre, decisión inaugural en la vida de un clown.

\section{ENtrar EN El JUEgo}

Un modo de organización del trabajo en escena tiene que ver con un código que pone el límite entre lo que es realidad y lo que no lo es, un punto de entrada al juego teatral y un punto final de ese juego. Ese límite lo dan el redoble del tambor y la nariz. "Cuando el actor entra en escena llevando su pequeña nariz — sostiene Lecoq - su rostro manifiesta un estado de indefensa disponibilidad» (Lecoq, 2004, pág. 213). Dice Chamé:

En los cursos de clown se la hago poner porque me parece que tienen que aprender a manejar una máscara frente a un público. Y a la vez simbolizar un personaje: sos vos pero no sos vos. Ponerse la nariz es un buen código para entrar en el juego, para decir «iVamos!» Es como 
el golpe de tambor que para mí es fundamental también para marcar el tiempo, el ritmo, y lo más importante que hay que mantener: el estar dentro y, al mismo tiempo, dejar fuera al personaje.

Una vez en el juego, se trabaja sobre tres conceptos fundamentales interconectados entre sí: atención, proyección, concentración.

- Una parte elemental del entrenamiento está ligado al registro de la atención, una atención divergente, ya que el clown debe estar atento al público, a sí mismo, a su partenaire y al entorno. Ese registro permite saber lo que funciona o no funciona en la escena, y poder acentuar ciertos momentos de conexión o modificar aquellos en los que no pasa nada, los momentos en que se está fracasando. En la conexión con los espectadores se trabaja también sobre un recurso muy puntual: «la mirada a público». Esta debe ser rápida y definida. Es muy específica, establece un vínculo de complicidad con los espectadores y por tanto no debe utilizarse banalmente.

- Otro ingrediente nodal en la formación tiene que ver con la búsqueda de la proyección escénica. Es esencial estar proyectado, tener la capacidad de llegar al público. Estar afuera y adentro al mismo tiempo, tener un contacto interno y un contacto con el público.

«Estar sintiendo algo mientras estás afuera y eso que estás sintiendo tiene que ayudarte positivamente a meterte adentro», explica el maestro.

- De ahí la relevancia de estar concentrado: «La concentración tiene que estar puesta en el registro de lo que está pasando y empezar a trabajar sobre eso». Si el actor está conectado percibe lo que funciona, y lo que no, con el público. Si no funciona - explica el director- no hay que ocultarlo, en todo caso es inútil disimularlo.

La línea que separa el éxito del fracaso es muy delgada. Se camina en una cuerda floja, testimonian los payasos. Chamé enfatiza que el éxito y el fracaso tienen el mismo valor. Hay que investigar adónde envía el fracaso. El fracaso no es un fin, es un medio. Si se trabaja con el fracaso se abren más lugares. Estar abierto, de eso se trata.

\section{Desarrollar los conflictos}

En su formación, el actor debe prepararse para enfrentar al público y trata de disimular cualquier error o incidente. Mientras que para el clown esos errores, esas dificultades, constituyen básicamente material 


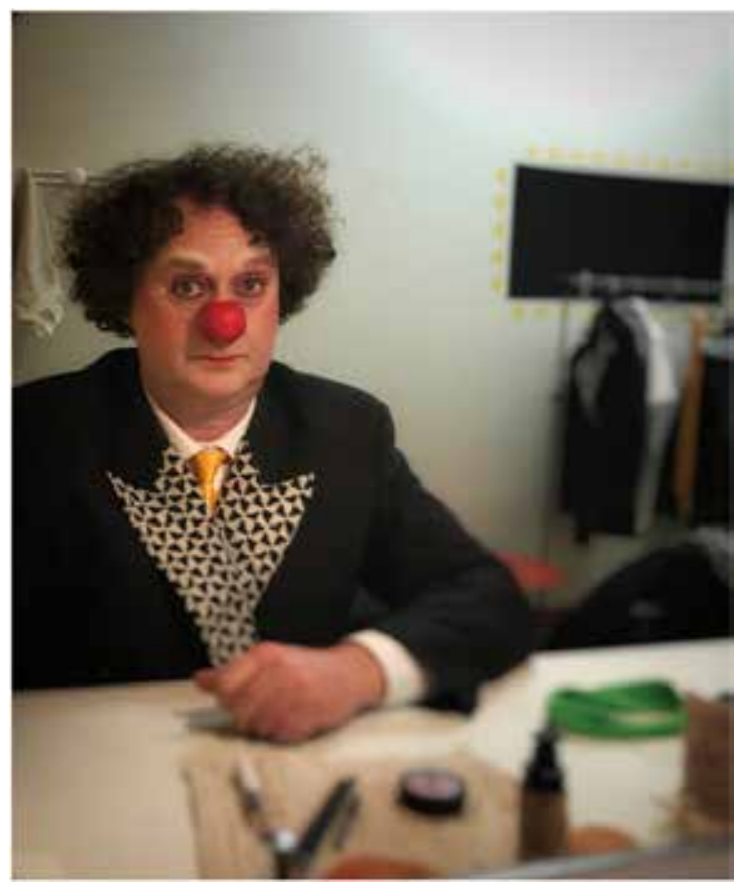

Gabriel Chamé Buendía por él mismo.

de trabajo. El payaso se alimenta de conflictos, de aprietos. Pero atraviesa esos obstáculos sin deprimirse. No puede permitirse la depresión, si lo hiciera correría el riesgo de deprimir al espectador. La energía del payaso tiene que ser liviana, trasuntar levedad y siempre salir hacia la acción. No importan sus padecimientos, un clown es positivo.

Un eje sustancial en el aprendizaje, conjuntamente con la atención, la concentración y la proyección, pasa por el desarrollo del juego teatral. En ese desarrollo la explotación del conflicto es particularmente relevante. En las improvisaciones se está abierto al impulso creativo, abierto a las imágenes. Pero una vez que se encuentra algo, es necesario particularizar los detalles de ese juego y desarrollarlo. Aprovechar al máximo lo que está sucediendo.

En la construcción artística, el volumen energético se pierde si se hacen muchas cosas. Se trata - explica el profesor-de ser más creativo con lo mismo, esto es, lo hilarante que se puede seguir descubriendo a partir del mismo material. Buscar aumentar la efectividad, estirar los 
conflictos, sacar mayor provecho cómico a cada acción. Para el clown, la dificultad es la posibilidad de trabajar en escena. El objetivo es encontrar más problemas de una misma cosa. En vez de saltear el problema, instruye Chamé, encontrar la dificultad profunda y desarrollarla.

El del clown, entonces, no es un trabajo de ir sumando, de ir agregando capas; por el contrario, es un trabajo de sustracción, de profundización, una suerte de revelado en negativo. Hay que aprender a renunciar, aprender a no abarcarlo todo. La renuncia posibilita la síntesis. Ahí se genera el hecho simple y por lo tanto, poético. En el universo clownesco, «menos es más». Menos cantidad y más energía. El clown es minimalista.

\section{Crear en el vacío}

Peter Brook desarrolló la idea de vacío como central en la creación teatral. «Es necesario crear un espacio vacío - dice- para que se produzca algo de calidad» (Brook, 2002b, pág. 73).

El vacío es un concepto clave en la poética de Gabriel Chamé Buendía. «Estamos asociados a un inconsciente colectivo y el pánico al vacío nos tiene agarrados - afirma. El payaso nos recuerda nuestra tragedia y la risa es una manera de soltar el pánico a la muerte». El vacío está siempre. En la creación todo es vacío. Hay que generar en el vacío.

«La tendencia del actor, sostiene el maestro, es un miedo a no saber qué hacer. Este tipo de trabajo teatral permite investigar sobre el miedo que tiene el actor al vacío de no saber qué hacer, a no entender. Y entra en lugares que lo llevan a descubrir cosas que no imaginaba.» Detrás de esa sensación de vacío aparecen cuestiones insospechadas, formas inesperadas. «El sentido del vacío consiste en que no pase nada para que, cuando pase, eso que pasa sea neto». El maestro retoma, a modo de ejemplo, un diálogo donde Brook asimila el concepto de vacío a una escultura primitiva. Lo atractivo de esa escultura era una forma muy precisa por fuera, y adentro nada, vacío.

Como artista, Chamé genera en el vacío, y como docente, insta a sus alumnos a asomarse a ese abismo, a generar en el vacío. El miedo a no saber qué hacer lleva al actor a automatizarse, se pone a hacer para tapar. Cuando se sobreactúa, se está tapando el vacío, se rellena algo 
que no hay que rellenar. Hay que dejar que se llene solo, que tome el lugar solo. Así lo dice:

La particularidad del mundo del payaso es esa falta aparente de estructura externa, esta cosa de que el tipo está ahí y aparentemente no hace nada, explica el maestro. Todo lo demasiado preparado es espectáculo. Si el payaso quiere hacer un espectáculo está mal ubicado. El clown no es parte del espectáculo, por eso hay que encontrar un vacío interno. Soltar, no preparar tanto, animarse a sostener, a sentirse perdido, a aguantar lo que viene. Lo fecundo para el actor es ir construyendo crecimiento y no hacer mucho al comienzo sólo porque, en rigor, no soporta no hacer nada. En fin, menos preparación y más acción.

\section{BUSCAR LO INTERIOR}

La escuela francesa del gesto de Étienne Decroux y sus discípulos, el mismo Lecoq, postulan la búsqueda de la expresión de la interioridad a través de la postura de la columna.

En este sentido Yves Lebreton (2011), en su reapropiación del artículo de Decroux Midefinición del teatro (1931), pone el foco en el acto físico radicado en el cuerpo, proyectado por el movimiento, como afirmación de la existencia. El acto sería - sostiene Lebreton - una suerte de fuerza de intervención o capacidad de escuchar; un lugar «donde la expresión y la comunicación se provocan mutuamente, ligándonos a nosotros mismos y a los demás en el flujo y reflujo del dar y recibir» (2011, pág. 2).

El acto debe ser vivo e integrar, en el instante de su realización, la totalidad de quien actúa. Las mímicas, los gestos de los brazos y de las manos, son demostrativos y explicativos si no encuentran sus orígenes en el eje del tronco. Observando a sus alumnos en escena, Chamé descubre una tendencia general a ponerse «explicativos»:

Si encuentran algo físicamente, sienten una inseguridad en lo que están encontrando y comienzan a utilizar los brazos. La expresión nunca parte de los brazos - agrega-; los brazos no cuentan, son como adornos. El movimiento potente que va a dar una sensación emocional siempre parte de la columna vertebral. Viene de adentro, del tronco y no de las extremidades. 


\section{Resultados DE UN VIAJE PEDAGÓGico}

El viaje propuesto por Chamé es un viaje de descubrimiento. Un grupo de actores y su maestro, reunidos en el espacio penumbroso de una sala teatral, se arriesgan a la aventura de internarse en un universo «otro», el del lenguaje clownesco. El juego, la inocencia, el absurdo, la vulnerabilidad, están en el centro de este universo.

A través de un entrenamiento riguroso de prácticas individuales y grupales, los actores se ejercitan en la recuperación del placer del juego, en la lucha por ganarle a la mente, entendiendo que el impulso del juego es muy cercano a lo que se busca en escena. La técnica elemental de «impulso, punto fijo, público» constituye la dinámica básica del aprendizaje. Se trabaja la proyección de la voz, la voz que es cuerpo; el efecto transformador del uso de máscaras. Se enfatizan la precisión rítmica de las acciones de los alumnos y la multiplicación de los problemas como materia indispensable de su payaso. Multiplicación del conflicto pero renuncia al exceso de acciones inconducentes que sólo apuntan a mitigar el miedo al vacío. Síntesis y simplicidad son el camino hacia la poesía. El objetivo no es hacer mucho, sino descubrir ese juego que florecerá en su desarrollo. Y, una vez descubierto, proyectarlo, «convidarlo al público», diría el clown Marcelo Katz (Grandoni, 2006, pág. 77).

No se trata, entonces, de un despliegue de destrezas, se trata de asumir riesgos creativos. Trasuntar una visión poética del mundo. «La payasada - sostiene Moreira - era una pintura abierta a la reflexión sobre lo no dicho, sobre la diferencia, sobre lo oculto y lo deseado; en síntesis, sobre la alteridad.» (Moreira, 2008, pág. 67).

El pedagogo, diría Lecoq, debe estar atento a que el actor no anticipe sus intenciones, a que esté siempre en estado de reacción y de sorpresa. Chamé estimula a sus alumnos a desestructurar, previniendo la repetición de fórmulas ya probadas que lleven a una conducta estereotipada: «Lo que era una gran verdad, puede convertirse en una gran mentira. Lo que aparentemente transmitía algo muy sincero después se convierte en un prototipo de algo.» (Chamé en Grandoni, 2006, pág. 139).

El docente no se limita a instruir a los actores en las técnicas del lenguaje clownesco. Pone el acento en la valorización del arte del clown en toda su complejidad. Alerta contra el éxito rápido y propone un camino de trabajo y humildad. Gabriel Chamé Buendía busca, amorosa $y$ firmemente, descubrir en cada alumno, en cada clown, de modo 
personalizado, los mecanismos propios. En este viaje compartido busca que se revele lo que le puede resultar efectivo a cada uno en ese mundo paralelo al mundo, en ese espacio-tiempo extra-cotidiano que es la escena. Allí donde el cuerpo del actor deviene cuerpo poético.

\section{A MOdO DE CONCLUSIÓN: SER Un CLOWN}

«La belleza no tiene otro origen que la herida», afirma Jean Genet (2012: 8). La belleza surgida del vacío y el dolor, en esa rara conjunción de dolor y levedad propia del universo clownesco, es el sustento filosófico de los seminarios de Gabriel Chamé Buendía. El clown, desde luego, nunca entró en el lenguaje del teatro realista. Es un arte poético. «Si hubiera de encontrarle un equivalente en el mundo de la literatura, el clown se acerca a la poesía, nunca a la narración o a la prosa», opina Chamé.

El pintor Wassily Kandinsky busca lo esencial anulando la coartada de la representación figurativa, para poder comunicar su «necesidad interior» solo con los componentes del arte pictórico: los puntos, las líneas, las formas y los colores. Este universo pictórico abstracto de profunda espiritualidad evoca el poema visual del universo clownesco. Un poema de acciones físicas donde la palabra no está necesariamente ausente, pero es una palabra que surge de la acción. El clown lo es porque tiene algo para decir. El clown dice, pero en su mundo lo que más importa es «cómo dice». Compone un texto de imágenes-acciones que configuran una cadena de significantes. Nunca es explicativo. Es el deseo moviéndose y produciendo por rizoma, diría Raquel Sokolowicz, retomando a Deleuze (Grandoni, 2006, pág. 30).

El clown tiene que ser simple y profundo, sostiene Chamé: «Con un trapito contar la historia del mundo». Un sentido profundamente humano está allí, presente en el clown, un actor que «no representa», un intérprete donde los sentidos fluyen. Tejido único entre emoción, cuerpo e imaginación. No es sólo la carcajada; es lo bello, el goce estético, lo humano en su vulnerabilidad, la inocencia, la sorpresa.

Dice Gabriel Chamé Buendía: «La gente se pregunta ¿qué es un clown? Y lo interesante es la no respuesta. No sabemos. La respuesta es que no hay respuesta a qué es un clown. Por eso existe y sobrevive». 


\section{Bibliografía}

Bergson, Henri (1986). La risa. Madrid: Editorial Espasa Calpe.

Brook, Peter (2002a). El espacio vacío, Arte y técnica del teatro. Barcelona: ed. Península.

Brook, Peter (2002b). La puerta abierta, Reflexiones sobre la interpretación y el teatro. Barcelona: Alba editorial.

Castro, Carolina, Ángela, 25/1/2013, La lógica del payaso es Jescubrir de qué se ríen y desarrollarlo, entrevista a Gabriel Chamé Buendía, Tiempo Argentino, disponible en: http://tiempo.infonews. com/2013/01/25/espectaculos-95224-la-logica-del-payaso-es-descubrir-de-que-se-rien-y-desarrollarlo.php

Dubatti, Jorge (2007). Filosofía del Teatro I, Convivio, Experiencia, Subjetividad. Buenos Aires: Atuel.

Gautré, Alain (2015). Texto en el programa de mano de Llegué para irme, espectáculo de Gabriel Chamé Buendía.

Genet, Jean (2012). El atelier de Alberto Giacometti. Buenos Aires: Fundación Proa.

Grandoni, Jorge (2006). Clown: Saltando los charcos de la tristeza. Buenos Aires: Libros del Rojas.

Jara, Jesús (2011) Los juegos teatrales del clown, Navegante de las emociones. Buenos Aires:Novedades Educativas.

Koss, Natacha (2009). Lecoq Jacques: el viaje, en Historia Jel Actor II. Del ritual dionisíaco a Tadeusz Kantor (coordinador Dubatti, Jorge). Buenos Aires: Colihue Teatro.

Lecoq, Jacques (2004). El cuerpo poético (Una pedagogía de la creación teatral). Barcelona: Alba Editorial.

Lebreton, Yves, 2011, El cuerpo manifiesto, disponible en: http://teatroarquitos.files.wordpress.com/2011/01/yves lebretonesp.pdf

Moreira, Cristina (2008). Las múltiples caras del actor. Buenos Aires: Inteatro (Instituto Nacional del Teatro).

Saavedra, Guillermo, (14/8/2014), Opiniones de un payaso, entrevista a Pierre Étaix, Perfil, disponible en: http://www.perfil.com/cultura/Opiniones_-de-un-payaso-20140222_0084.html

Santillán Juan José, (25/5/2013), Payasos que se la toman en serio, Clarín, disponible en: http://www.clarin.com/espectaculos/teatro/Payasos_toman-serio 0 917908254.html 
Trucco, Florencia, (24/1/2013), Uno solo contra la vorágine, La Nación, disponible en: http://servicios.lanacion.com.ar/archivo/2013/01/24/espectaculos/008

Yaccar, María Daniela, (4/11/2010), La risa es una manera de soltar el miedo a la muerte, Página 12, disponible en: http://www.paginal2.com. ar/diario/suplementos/espectaculos/10-19803-2010-11-04. $\underline{\mathrm{html}}$

\section{Notas}

1 Quidam, Cirque du Soleil, clown (1999/2004).

2 Gabriel Chamé desarrolla su actividad como director, investigador, actor y docente en Europa y Latinoamérica, principalmente en España y Francia, donde reside. Trabaja en La Cascade, Maison des arts Ju clown et Ju cirque. Viaja con frecuencia a Buenos Aires donde presentó su unipersonal Llegué para irme (2007), que define como tragicomedia metafísica o «Meloclown»,con varias reposiciones, estuvo en cartel en el teatro Caras y Caretas 2037 en 2019. Estrenó en 2014 Last Call (Última Llamada) en el Teatro Nacional Cervantes (varias reposiciones, en 2017 y 2018 en el teatro El Picadero). Antes, dirigió y adaptó Othelo, termina mal (2013), su particular reescritura de la tragedia de Shakespeare (actualmente en cartel Teatro Caras y Caretas 2037).

3 Dicta cursos de clown, bufón, melodrama y máscara neutra.

4 Observaciones tomadas en sus clases de Historia del Teatro Universal, Carrera de Artes, Facultad de Filosofía y Letras, Universidad de Buenos Aires, 2014.

5 Como ya se señaló, cuando no se explicita otra fuente, todas las declaraciones de Chamé en el presente artículo fueron tomadas por la autora en los seminarios dictados por el artista entre 2013 y 2016.

6 Entrevista con la autora, Centro Cultural de la Cooperación, 9/9/2013.

7 Entrevista con la autora, referida anteriormente.

8 Entrevista de Escuela de Espectadores de Buenos Aires, coordinada por Jorge Dubatti, 9/9/2013. 
